\title{
Fear Extinction Memory Consolidation Requires Potentiation of Pontine-Wave Activity during REM Sleep
}

\author{
Subimal Datta ${ }^{1,2,3}$ and Matthew W. 0'Malley ${ }^{1,2}$ \\ ${ }^{1}$ Laboratory of Sleep and Cognitive Neuroscience, and Departments of ${ }^{2}$ Psychiatry and ${ }^{3}$ Neurology, Boston University School of Medicine, Boston, \\ Massachusetts 02118
}

\begin{abstract}
Sleep plays an important role in memory consolidation within multiple memory systems including contextual fear extinction memory, but little is known about the mechanisms that underlie this process. Here, we show that fear extinction training in rats, which extinguished conditioned fear, increased both slow-wave sleep and rapid-eye movement (REM) sleep. Surprisingly, $24 \mathrm{~h}$ later, during memory testing, only $57 \%$ of the fear-extinguished animals retained fear extinction memory. We found that these animals exhibited an increase in phasic pontine-wave ( $\mathrm{P}$-wave) activity during post-training $\mathrm{REM}$ sleep, which was absent in the $43 \%$ of animals that failed to retain fear extinction memory. The results of this study provide evidence that brainstem activation, specifically potentiation of phasic P-wave activity, during post-training REM sleep is critical for consolidation of fear extinction memory. The results of this study also suggest that, contrary to the popular hypothesis of sleep and memory, increased sleep after training alone does not guarantee consolidation and/or retention of fear extinction memory. Rather, the potentiation of specific sleep-dependent physiological events may be a more accurate predictor for successful consolidation of fear extinction memory. Identification of this unique mechanism will significantly improve our present understanding of the cellular and molecular mechanisms that underlie the sleep-dependent regulation of emotional memory. Additionally, this discovery may also initiate development of a new, more targeted treatment method for clinical disorders of fear and anxiety in humans that is more efficacious than existing methods such as exposure therapy that incorporate only fear extinction.
\end{abstract}

\section{Introduction}

In both humans and animals, memories of fearful experiences can lead to enduring alterations in emotion and behavior. It is known that sleep plays a natural emotional regulatory role after stressful and traumatic events, yet sleep is often disrupted after these events (Lavie, 2001). This regulatory role is vital, and there is ample evidence demonstrating that persistence of sleep disturbances, particularly of REM sleep, is predictive of developing symptoms of post-traumatic stress disorder (PTSD) (Lavie, 2001; Mellman et al., 2007). A core symptom of PTSD frequently reported by patients is the persistence of fear-provoking memories that they are unable to extinguish (Rothbaum and Davis, 2003; Anderson and Insel, 2006). At present, exposure therapy is considered one of the most effective evidence-based treatments for anxiety disorders (Cukor et al., 2010). Over the last two decades, contextual fear extinction training, an animal analog of exposure therapy that employs classical fear conditioning, has become an ideal experimental model for studying the mechanisms of fear

Received Nov. 30, 2012; revised Jan. 22, 2013; accepted Jan. 24, 2013.

Author contributions: S.D. designed research; S.D. and M.W.O. performed research; S.D. and M.W.O. analyzed data; S.D. and M.W.O. wrote the paper.

This work was supported by National Institutes of Health Research Grants NS34004 and MH59839 and Boston University School of Medicine. We thank Dr. Edward F. Pace-Schott for his critical reading and constructive suggestions to improve the quality of this manuscript.

The authors declare no competing financial interests.

Correspondence should be addressed to Professor Subimal Datta, Boston University School of Medicine, 85 East Newton Street, Suite M-902, Boston, MA 02118. E-mail: Subimal@bu.edu.

DOI:10.1523/JNEUROSCI.5525-12.2013

Copyright $\odot 2013$ the authors $\quad 0270-6474 / 13 / 334561-09 \$ 15.00 / 0$ extinction (Bouton et al., 2006; Graham and Milad, 2011; Milad and Quirk, 2012). Successful fear extinction training has been shown to ameliorate sleep disturbances that are induced by fear conditioning in rats (Wellman et al., 2008). Conversely, adequate sleep following fear extinction training has been shown to increase the efficacy of this training by promoting the generalization of extinction in humans (Pace-Schott et al., 2012). Collectively, the results of these studies support the notion that sleep is a critical component in the regulation of emotional memory.

It is now widely accepted that fear extinction does not erase conditioned fear, but rather creates a new memory that coexists and competes with the fearful memory when the fear context and/or cue is again encountered (Bouton et al., 2006; Maren, 2007). Over the last four decades, sleep has been shown to confer a beneficial effect on many different types of learning and memory, and more recently, mounting evidence has suggested that separate sleep states and their specific physiological processes are differentially involved in the steps of memory consolidation (Datta, 2010; Diekelmann and Born, 2010). Some recent studies have shown that a lack of REM sleep impairs recall of fear extinction memory (Silvestri, 2005; Fu et al., 2007; Silvestri and Root, 2008; Spoormaker et al., 2010, 2012). However, the roles of other sleep stages in extinction memory, as well as the important physiological processes within each sleep stage, have not yet been identified.

We conducted experiments to identify sleep-associated variables involved in the consolidation of contextual fear extinction memory in rats under conditions that naturally increase or de- 
crease sleep variables without imposing additional stress. The results of this study show that fear extinction training increases both slow-wave sleep (SWS) and REM sleep. Additionally, the consolidation and retention of extinction memory requires potentiation of phasic $\mathrm{P}$-wave activity in the brainstem, an important area in the REM-sleep regulating network. This work has clinical implications for the treatment of fear and anxiety disorders and practical applications for the modulation of learning and memory.

\section{Materials and Methods}

Subjects and housing. Fifty-two adult male Sprague Dawley rats (Charles River Laboratories), weighing between 250 and $350 \mathrm{~g}$, were used in the experiments. Rats were housed individually at $24^{\circ} \mathrm{C}$ on a $12 / 12 \mathrm{~h}$ light/ dark cycle (lights on at 7:00 A.M.) with ad libitum access to food and water. Experiments were performed in accordance with the NIH Guide for the Care and Use of Laboratory Animals and were approved by the Boston University Animal Care Committee (AN-14085). Additional care was taken to ensure that any potential discomfort was eliminated and the number of animals used was minimized. To reduce additional stress that might have been imposed by experimental handling, animals underwent a period of habituation during which they were gently handled daily for 15-20 min between 9:00 A.M. and 10:00 A.M. (beginning 1 week before surgery and continuing up to the experimental recording sessions).

Surgical procedures. All surgical procedures were performed stereotaxically under aseptic conditions. Animals were anesthetized with pentobarbital (40 mg/kg, i.p; Ovation Pharmaceuticals), placed in the stereotaxic apparatus, and secured using blunt rodent ear bars, as described previously (Paxinos and Watson, 1997). The appropriate depth of anesthesia was judged by the absence of both palpebral reflexes and a response to tail pinch. Core body temperature was maintained at $37 \pm$ $1^{\circ} \mathrm{C}$ with a thermostatic heating pad and a rectal thermister probe. To record behavioral states of vigilance, cortical electroencephalogram (EEG), dorsal neck muscle electromyogram (EMG), hippocampal EEG (to record theta wave activity), and pontine EEG (to record P-wave activity), recording electrodes were chronically implanted in the rats, as described previously (Datta, 2000). All electrodes were secured to the skull with dental acrylic, and the electrodes were then crimped to miniconnector pins and brought together in a plastic connector. Upon completion of the surgical procedure, animals were administered saline ( $5 \mathrm{cc}$, s.c.) to prevent dehydration, ampicillin $(50 \mathrm{mg} / \mathrm{rat}$, i.m.; Bristol-Myers Squibb Company) to control potential postsurgical infection, and buprenorphine $(0.05 \mathrm{mg} / \mathrm{kg}$, s.c; Ben Venue Laboratories) to control potential postoperative pain. Immediately after surgery, animals were placed in recovery cages and monitored for successful recovery from anesthesia and surgery.

Polygraphic recordings and determination of behavioral states. To record cortical EEG, EMG, hippocampal EEG, and pontine EEG in free-moving conditions, each head plug was mated to a male connector attached to a commutator. Signals from the commutator went to a polygraph (Grass Model 15 Neurodata Amplifier System, Astro-Med), located in the next room, via its electrode board (located close to the recording chamber). To identify experimental effects on sleep and wakefulness, polygraphic data were captured online in a computer using "Gamma" software (Grass product group, Astro-Med). One investigator blinded to the treatment conditions scored this captured data visually using "Rodent Sleep Stager" software (Grass product group, Astro-Med). Four behavioral states were distinguished: wakefulness (W), SWS, transitional sleep between SWS and REM sleep (tS-R sleep), and REM sleep; these states were scored in successive $5 \mathrm{~s}$ epochs. The physiological criteria used to identify these sleep-wake (S-W) states are described in detail in an earlier publication (Datta et al., 2004).

Adaptation recording session. After 3-7 d of postsurgical recovery time, rats were habituated to the experimenter, the sound-attenuating recording cage (electrically shielded: $76.2 \times 45.7 \times 45.7 \mathrm{~cm}$ ), and free-moving polygraphic recording (Grass Model 15 Neurodata Amplifier System, Astro-Med) conditions for 7-10 d. During these periods of recovery and habituation, rats were housed under the same 12/12 h light/dark cycle with ad libitum access to food and water. Rats were polygraphically recorded during these habituation sessions, which took place between 10:00 A.M. and 4:00 P.M. - a time when rats are normally sleeping. These $6 \mathrm{~h}$ habituation sessions were used as the baseline recordings for electrode testing and monitoring of daily variations in S-W activity. The last day of these adaptation recording sessions was determined when, for three consecutive days, day-to-day variation in the percentage of time spent in REM sleep was $<5 \%$ of the total amount of time spent in REM sleep. During these final three baseline recording sessions, the pontine EEG was studied carefully to identify rats with good-quality $\mathrm{P}$-wave activity during REM sleep. Of the original 52 rats, 32 exhibited good-quality P-waves, while the other 20 expressed very few or no P-waves during REM sleep. In these 20 rats, the P-wave-recording electrodes may have been unintentionally placed outside of the $\mathrm{P}$-wave generator; thus, these rats were not included in this study. Study animals were equal in terms of their S-W variables and P-wave activity at baseline, as evidenced by the final $6 \mathrm{~h}$ baseline recording session, during which there was no significant group effect on the total percentages of time spent in W, SWS, tS-R, and REM sleep, nor was there any significant group effect on P-wave density.

Contextual fear conditioning apparatus and procedure. A standard testing chamber $(30.5 \times 24.1 \times 21.0 \mathrm{~cm}$; Standard modular test chamber, ENV-008; Sound attenuating cubicle, ENV-022MD; Med Associates), constructed from aluminum (side walls) and Plexiglas (rear wall, ceiling, and hinged front door) was used. The floor of the chamber consisted of 19 stainless-steel rods (4 $\mathrm{mm}$ in diameter) spaced $1.5 \mathrm{~cm}$ apart (centerto-center), which were wired to a shock source and solid-state grid scrambler for the delivery of foot-shocks. This chamber was situated in a sound-attenuating cabinet, which itself was located in a brightly lit and isolated room. A ventilation fan in the cabinet provided background noise $(65 \mathrm{db})$, and a closed circuit video camera mounted inside the cabinet videotaped the behavior of the rat inside the chamber. Freeze responses were video-recorded and analyzed online using customized computer software (Med Associates). Freezing behavior was defined as the absence of movement with the exception of breathing (sample rate: 30 frames/s; minimum freeze duration: 15 frames; \% freezing in bin durations of $5 \mathrm{~min}$ ). The contextual fear acquisition procedure began with the transportation of naive rats (in a clear plastic cage) from their housing room to the behavioral testing room, where they were then randomly selected either to receive foot-shocks ( $n=24$ rats) or to be used as the no-shock control ( $n=8$ rats). Five minutes after arrival, rats were placed inside the testing chamber for $2 \mathrm{~min}$ of adaptation. Following adaptation, the foot-shock-receiving rats underwent 10 trials of shock exposure, which consisted of unannounced (no light or tone) $1 \mathrm{~s}$ scrambled foot-shocks $(1.0 \mathrm{~mA})$ with variable intervals $(0.5-2.0 \mathrm{~min})$. One minute after the end of the last trial, rats were removed from the testing chamber. The procedure for the control rats was identical, except that no shock was administered. Each rat was alone inside the testing chamber for a period of $15 \mathrm{~min}$ (between 9:40 A.M. and 9:55 A.M.). The testing chamber was cleaned and disinfected with soapy water and chlorine dioxide disinfectant (MB-10, Quip Laboratories) before and after each use.

Contextual fear extinction training. Approximately $24 \mathrm{~h}$ after fear acquisition, rats were brought to the behavioral testing room for fear memory testing followed by fear extinction training. Five minutes after arrival (at 9:10 A.M.), each of the 24 fear-acquired rats and 8 control rats was placed singly in the testing chamber, without any shock. The first $15 \mathrm{~min}$ (3 blocks of $5 \mathrm{~min}$ ) of this session served as a fear memory test session. After this 15 min period, 16 of the fear-acquired rats and all 8 control rats were left undisturbed, inside the chamber to continue their respective 45 min sessions of fear extinction training and control training (9:10 A.M. to 9:55 A.M.), while the other 8 fear-acquired rats were promptly removed from the chamber (9:10 A.M. to 9:25 A.M.; hereafter this group of 8 animals will be labeled "animals with no extinction," No-ext; Fig. 1A). Using these two different lengths of shock-free reexposure allowed us to compare the specific effects of a short versus long fear extinction training period-15 min versus $45 \mathrm{~min}$.

During fear memory testing and fear extinction training, rat behavior was recorded and analyzed as the total percentage of freezing time in successive bin durations of $5 \mathrm{~min}$. The most commonly used behavioral 

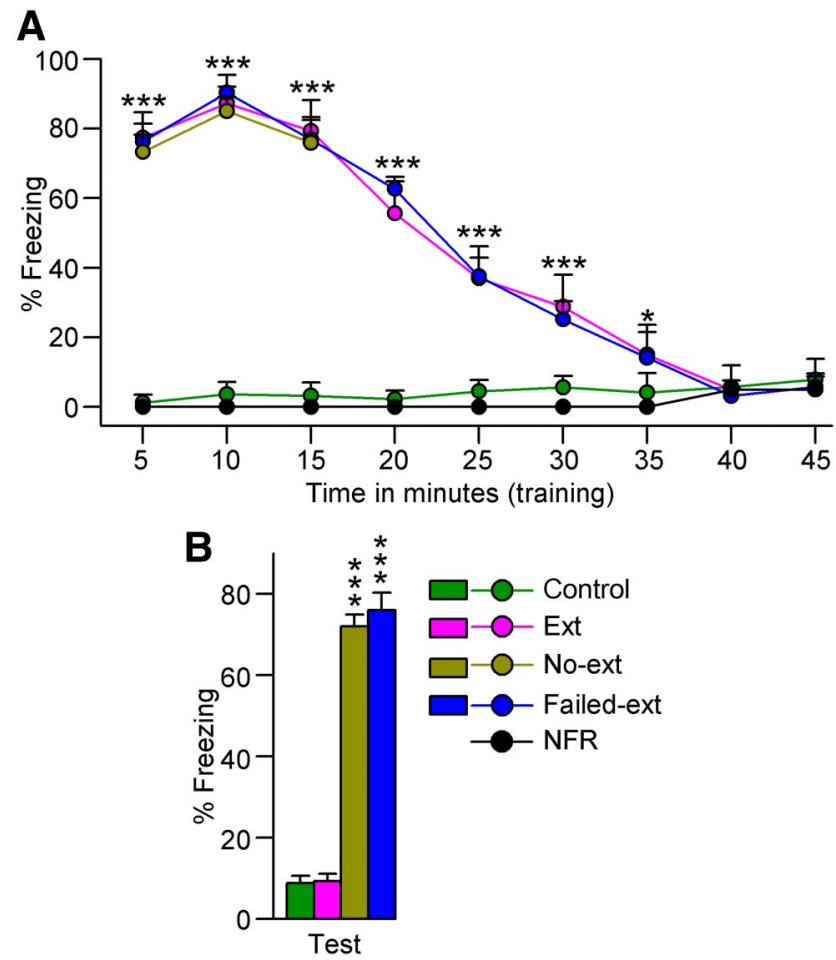

Figure 1. Fear extinction memory training and subsequent testing of fear extinction memory. $\boldsymbol{A}$, Progression of freezing behavior (\% of freezing) during fear extinction training. Note, most rats that received foot-shock during fear acquisition (Ext, $n=8$; No-ext, $n=8$; Failed-ext, $n=6$ ) exhibited high levels of freezing behavior during fear extinction training during the first $10 \mathrm{~min}$, which then gradually declined to the level of the nonshocked control (Control, $n=8$ ) rats. Also, note that some rats that received foot-shock during fear acquisition (NFR, $n=2$ ) did not exhibit any freezing behavior. $\boldsymbol{B}$, Freezing behavior during fear extinction memory testing. Note the significant variation in freezing among rats that underwent $45 \mathrm{~min}$ of fear extinction training (Ext versus Failed-ext). Also note the significantly higher level of freezing in rats that underwent only $15 \mathrm{~min}$ of fear extinction training (No-ext) compared with some rats that underwent 45 min of training (Ext). Error bars represent SEM.

measure to assess fear during shock training or context/cue reexposure is freezing. Greater percentage of freezing during contextual/cued fear conditioning test (reexposure) is interpreted as stronger fear memory; and very low or no fear during contextual/cued fear extinction training or test is interpreted as stronger fear extinction (Blanchard and Blanchard, 1969; Doyère et al., 2000). Of the 24 animals that underwent the fear acquisition protocol, 22 exhibited a very high freezing response $(>70 \%)$ during fear memory testing, indicative of a high level of conditioned fear. To our surprise, the other two rats exhibited very little to no freezing $(<10 \%$; hereafter this group will be labeled "animals with no fear response," NFR; Fig. 1A), indicating these two animals did not show behavioral evidence of fear memory; therefore, these two animals were removed from this study. The results of the 22 fear-acquired rats suggest that, like cue-dependent (light or auditory signal) fear conditioning paradigms, this fear acquisition paradigm is effective for developing longterm fear memory (Choi et al., 2010; Peters et al., 2010).

Contextual fear extinction memory testing. On the next day ( $24 \mathrm{~h}$ after fear extinction training), all rats were returned individually to the same freezing-behavior testing chamber one final time for a 5 min session to test recall of fear extinction memory (9:55 A.M. to 10:00 A.M.). During this test, all animals in the No-ext group exhibited high levels of freezing behavior, as expected, indicating the presence of only fear memory (Fig. $1 B$ ). However, 6 of the 14 fear extinction-trained rats (disregarding the 2 NFR animals) also exhibited very high levels of freezing ( $>70 \%)$, again indicative of an absence of fear extinction memory (hereafter this group of animals will be labeled "animals with failed extinction memory," Failed-ext; Fig. $1 B$ ). The other 8 fear extinction-trained rats exhibited very little to no freezing $(<10 \%)$ during fear extinction memory testing, as expected, indicating the presence of fear extinction memory (hereafter this group of animals will be labeled "animals with extinction memory," Ext; Fig. $1 B)$. Similarly, the control group of rats exhibited almost no freezing $(<10 \%)$.

Statistical analysis. Results are presented as means \pm SEM. Freezing data were tabulated as total percentage of time spent in freezing behavior in blocks of $5 \mathrm{~min}$. S-W and P-wave density data were tabulated as described in our earlier publication (Datta et al., 2004). Statistical significance was assessed using a one-factor or two-factor ANOVA followed by a post hoc Bonferroni's multiple-comparison test to determine the difference between groups. Results were considered significant at ${ }^{\star} p<0.05$, ${ }^{* *} p<0.01$, and ${ }^{* * *} p<0.001$. Spearman's rank correlation analysis was performed to assess the relationship between extinction memory and $\mathrm{P}$-wave density following fear extinction training. All statistical analyses were performed using Graphpad Prism statistical software (v5.0; Graphpad Software).

\section{Results}

Effects of experimental protocol on the determination of animal groups

Experimental animals were divided into four groups: three groups were designated at the outset of experimentation based on experimental design and a fourth group emerged unexpectedly during experimentation. The three predetermined groups of animals were the extinction (Ext, $n=8$ rats), no extinction (No-ext, $n=8$ rats), and Control ( $n=8$ rats) groups. Ext animals underwent a session of fear acquisition, which was followed $24 \mathrm{~h}$ later by a 45 min session of fear extinction training (the first 15 min of which also served as the fear memory testing session), which was followed $24 \mathrm{~h}$ later by a session of fear extinction memory testing. During this fear extinction memory testing session, Ext animals exhibited little or no freezing behavior, indicating successful extinction of the fear memory. No-ext animals were exposed to the same experimental procedure as Ext animals but received only 15 min of fear extinction training (thus only the fear memory testing portion). These animals, unlike Ext animals, exhibited high levels of freezing on the fear extinction memory test day, indicating a lack of extinction of the fear memory. Control animals were exposed to the same experimental procedure as Ext animals but received no foot-shock during fear acquisition. As expected, these animals exhibited little or no freezing behavior during fear extinction memory testing. Animals from the fourth experimental group, Failed-ext ( $n=6$ rats), received identical experimental treatment to that of Ext animals. However, unlike Ext animals, Failed-ext animals exhibited high levels of freezing behavior during fear extinction memory testing, again indicating a lack of extinction of the fear memory. These collective results (Fig. 1B) suggest that fear extinction memory consolidation may be affected by two factors: (1) duration of fear extinction training and (2) variability among individual conspecific animals.

\section{Length of training is critical to the success of fear extinction memory consolidation}

One of the most important questions regarding fear extinction memory consolidation is whether the duration of extinction training matters. A qualitative comparison of the freezing behaviors exhibited by Ext and No-ext animals during fear extinction memory testing (described above) does indeed implicate fear extinction training duration as a significant factor in fear extinction memory consolidation. This notion is further supported by the results of a one-factor ANOVA on the percentages of time spent freezing during fear extinction memory testing $\left(F_{(3,26)}=190, p<\right.$ $0.001)$, which indicated varying levels of fear extinction memory among the different groups of animals. Specifically, freezing be- 
havior during fear extinction testing was not significantly different between Ext and Control animals $\left(t_{(16)}=0.14\right.$; Bonferroni post-tests; Fig. $1 B$ ), but compared with these two groups, freezing behavior was significantly greater in No-ext animals $\left(t_{(15)}>17\right.$, $p<0.001$; Fig. $1 B$ ). These results suggest that Ext animals consolidated fear extinction memory to a point that the experimental context was no longer interpreted as a threat of aversive footshock, which in turn indicates that a $24 \mathrm{~h}$ period following fear extinction training is sufficient for successful consolidation of fear extinction memory. Also, these results indicate that No-ext animals failed to properly consolidate fear extinction memory. Thus, it is reasonable to presume that fear extinction training duration (Ext: $45 \mathrm{~min}$ vs No-ext: $15 \mathrm{~min}$ ) is a critical factor in the fear extinction memory consolidation process. Additionally, it appears that, for this particular experimental method of fear acquisition and extinction, successful consolidation of fear extinction memory requires between 15-45 min of fear extinction training.

To more precisely approximate the amount of training required for successful consolidation of fear extinction memory, we examined the freezing behavior exhibited by animals during the 45 min training session. A two-way ANOVA of the percentages of time spent freezing during this fear extinction training indicated a significant main effect of group $\left(F_{(2,152)}=460, p<0.001\right)$, time $\left(F_{(8,152)}=350, p<0.001\right)$, and group $\times$ time interaction $\left(F_{(16,152)}=110, p<0.001\right)$. Further analysis (Bonferroni posttests) revealed that the percentages of freezing time in Ext and Failed-ext animals were not significantly different, but compared with the baseline freezing values in the Control group, these percentages were significantly greater throughout the majority of fear extinction training (Fig. 1A). More specifically, compared with Control animals, at all time intervals between 5 and $35 \mathrm{~min}$, freezing behavior was significantly higher in both Ext (5-30 min: $t_{(15)}$ values $>7.9, p<0.001 ; 35$ min: $t_{(15)}=3.7, p<0.05$; Fig. $1 A$ ) and Failed-ext (5-30 min: $t_{(13)}$ values $>6.2, p<0.001 ; 35 \mathrm{~min}$ : $t_{(13)}=3.2, p<0.05$; Fig. $\left.1 A\right)$ animals; but at 40 and $45 \mathrm{~min}$, freezing behavior was no longer significantly greater in Ext (40 $\min : t_{(15)}=0.3, p>0.05 ; 45$ min: $t_{(15)}=0.98, p>0.05$; Fig. $\left.1 A\right)$ or Failed-ext (40 min: $t_{(13)}=0.82, p>0.05 ; 45 \mathrm{~min}: t_{(13)}=0.65$, $p>0.05$; Fig. $1 A$ ) animals. These collective data indicates that, despite demonstrating different levels of fear extinction memory consolidation, Ext and Failed-ext animals were in fact similar in terms of their acquisition of fear extinction memory. Moreover, it appears that successful acquisition of fear extinction memory does not guarantee its retention. Additionally, these results implicate $35 \mathrm{~min}$ as the approximate duration of training required for successful acquisition of fear extinction memory.

\section{Inherent variability among conspecific animals affects fear extinction memory consolidation}

Another central question concerning fear extinction memory consolidation is to what extent, if any, is this process affected by individual variation among conspecific animals. As mentioned earlier, during fear extinction memory testing Ext animals exhibited minimal freezing behavior compared with Control animals, while, compared with these two groups, Failed-ext animals exhibited high levels of freezing behavior $\left(t_{(13)}\right.$ values $>17$, $p<0.001$; Bonferroni post-test; Fig. 1B). Since this apparent discrepancy in fear extinction memory consolidation could not be attributed to a difference in experimental protocol (as was the case with No-ext animals), a closer look at the other testing parameters was mandated. First, we examined fear memory testing parameters, based on the fact that, conceptually, development of fear extinction memory competes with the original fear memory, making it more difficult to develop fear extinction memory in animals with stronger fear memory. Thus, a significantly stronger fear memory in Failed-ext animals could have been responsible for these animals' failure to develop fear extinction memory. A two-way ANOVA did in fact reveal a significant main effect of group $\left(F_{(3,52)}=640, p<0.001\right)$, time $\left(F_{(2,52)}=40, p<0.001\right)$, and group $\times$ time interaction $\left(F_{(6,52)}=3.6, p<0.01\right)$. However, post hoc comparisons (Bonferroni post-tests) on the percentages of time spent in freezing in each of the three 5 min blocks $(5,10$, and $15 \mathrm{~min}$ ) of the fear memory testing session revealed these percentages to be significantly higher in all of the fear-acquired animals (Ext: $t_{(15)}$ values $>27, p<0.001$; No-ext: $t_{(15)}$ values $>$ $26, p<0.001$; Failed-ext: $t_{(13)}$ values $\left.>76, p<0.001\right)$ compared with the Control animals (Fig. $1 A$ ), but not statistically different among the three fear-acquired groups. These results demonstrate that, behaviorally, Ext and Failed-ext animals expressed equally high levels of fear throughout the 15 min fear memory test. Therefore, the variability in fear memory consolidation demonstrated by Ext and Failed-ext animals during fear extinction memory testing is not likely to have been caused by differences in the strength of fear memory.

We then examined fear extinction training parameters and, as detailed earlier, Ext and Failed-ext animals exhibited similar acquisition of extinction memory during training. Thus, collectively, based on the lack of any tangible differences in experimental protocol, fear acquisition parameters, or fear extinction training parameters, it is logical to presume that an unknown biological variability among individual conspecific animals is also a critical factor in the process of fear extinction memory consolidation. To identify this unknown variable, we then examined the behavioral and physiological variables of the S-W cycle.

\section{Extinction of fear responses during reexposure to the fear context decreases wakefulness and increases slow-wave sleep}

To determine the effects of abolished context-associated fear on $\mathrm{W}$ and SWS immediately after fear extinction and control training, $6 \mathrm{~h} \mathrm{~S}-\mathrm{W}$ activity recordings were analyzed from the Ext, No-ext, Failed-ext, and Control animals. During these recording periods, the total percentages of time spent in $\mathrm{W}$ indicated significant (two-factor ANOVA) main effects of group $\left(F_{(3,130)}=71\right.$, $p<0.001)$, time $\left(F_{(5,130)}=56, p<0.001\right)$, and group $\times$ time interaction $\left(F_{(15,130)}=26, p<0.01\right)$. During the first $2 \mathrm{~h}$, compared with the Control, No-ext animals spent significantly more time in $\mathrm{W}\left(t_{(15)}\right.$ values $>6.8, p<0.001$; Bonferroni post-tests $)$, indicating that the reminder of context-associated fear increased $\mathrm{W}$ (Fig. 2). However, during this same $2 \mathrm{~h}$ period, compared with Control animals, both Ext $\left(t_{(15)}\right.$ values $\left.>7.5, p<0.001\right)$ and Failed-ext animals $\left(t_{(13)}\right.$ values $\left.>6.0, p<0.001\right)$ spent significantly less time in $\mathrm{W}$ (Fig. 2). These results indicate that the successful acquisition of the context-associated behavioral fear response not only blocked fear reminder-induced increases in $\mathrm{W}$, but also reduced $\mathrm{W}$ to levels below normal baseline levels.

A two-factor ANOVA on the total percentages of time spent in SWS indicated significant main effects of group $\left(F_{(3,130)}=36\right.$, $p<0.001)$, time $\left(F_{(5,130)}=34, p<0.001\right)$, and group $\times$ time interaction $\left(F_{(15,130)}=21, p<0.01\right)$. During the first $2 \mathrm{~h}$, No-ext animals spent significantly less time in SWS compared with Control animals $\left(t_{(15)}\right.$ values $>6.9, p<0.001$; Bonferroni post-tests; Fig. 3). This result indicates that the reminder of contextassociated fear decreased SWS. On the contrary, during the same $2 \mathrm{~h}$ period, compared with Control animals, both Ext $\left(t_{(15)}\right.$ val- 


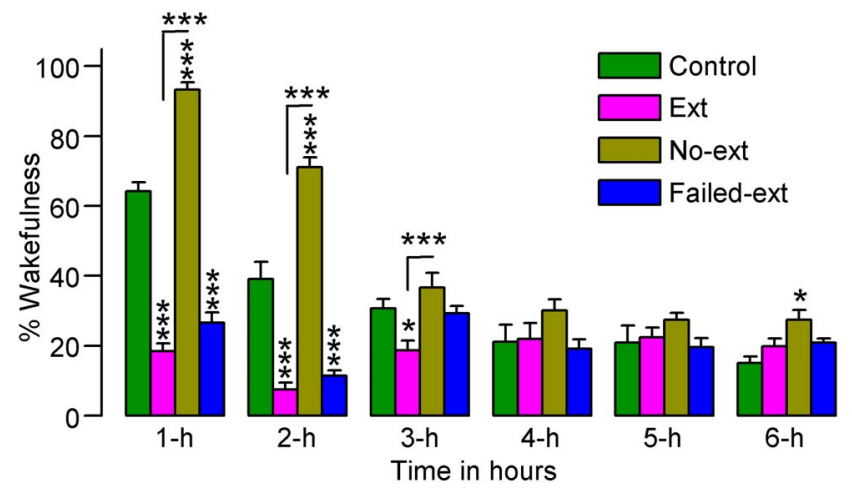

Figure 2. Effects of 45 min fear extinction training (Ext, $n=8$; Failed-ext, $n=6$ ) versus 15 min fear extinction training (No-ext, $n=8$ ) on the percentage of time spent in wakefulness. These effects were observed during the $6 \mathrm{~h}$ sleep-wake recording period that immediately followed fear extinction training. Note the significant decrease in wakefulness during the first $2 \mathrm{~h}$ of sleep - wake recording in rats that received $45 \mathrm{~min}$ of fear extinction training and the significant increase in wakefulness during the same time period in rats that received only $15 \mathrm{~min}$ of fear extinction training. Error bars represent SEM; ${ }^{*} p<0.05,{ }^{* * *} p<0.001$.

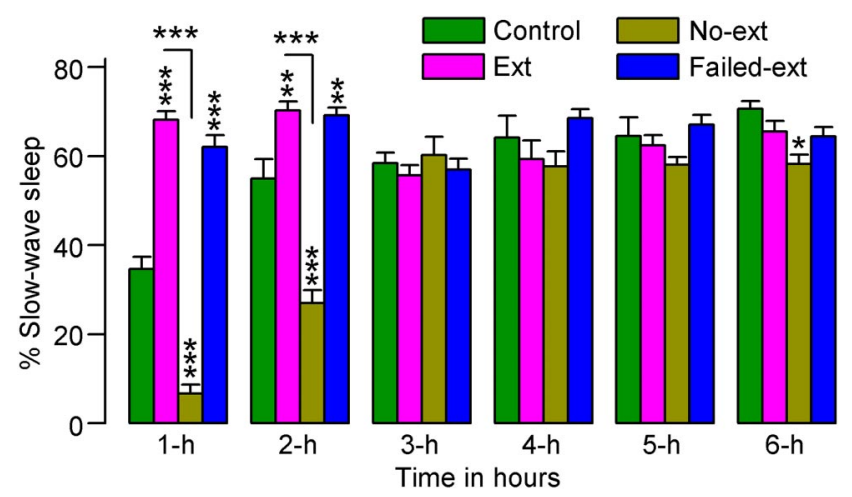

Figure 3. Effects of 45 min versus 15 min fear extinction training on the percentage of time spent in slow-wave sleep. These effects were observed during the $6 \mathrm{~h}$ sleep-wake recording period that immediately followed fear extinction training. Note the significant increase in slowwave sleep during the first $2 \mathrm{~h}$ of sleep - wake recording in rats that received $45 \mathrm{~min}$ of fear extinction training (Ext, $n=8$; Failed-ext, $n=6$ ), and the significant decrease in slow-wave sleep during the same time period in rats that received only $15 \mathrm{~min}$ of fear extinction training (No-ext, $n=8$ ). Error bars represent SEM; ${ }^{* *} p<0.01,{ }^{* * *} p<0.001$.

ues $>3.8, p<0.01)$ and Failed-ext $\left(t_{(13)}\right.$ values $\left.>3.3, p<0.01\right)$ animals spent significantly more time in SWS. These data suggest that the acquisition of the context-associated behavioral fear extinction memory not only blocked fear reminder-induced decreases in SWS, but also actively increased SWS to levels above normal baseline levels. Collectively, our results on W and SWS suggest that S-W disturbances normally experienced by both humans and animals following reexposure to a fear context could be ameliorated by successful training to extinguish behavioral signs of fear.

\section{Acquisition of contextual fear extinction memory increases the amount of time spent in P-wave-associated behavioral states}

In humans and many other mammals, including rats, $\mathrm{P}$-waves are normally present only during the behavioral states of $t S-R$ sleep and REM sleep. Therefore, these two stages of sleep are considered P-wave-associated sleep states (Datta, 2000). In all four experimental groups (Ext, No-ext, Failed-ext, and Control), the total percentages of time spent in $\mathrm{tS}-\mathrm{R}$ sleep were relatively low, compared with other S-W states; however, a two-factor ANOVA on the total percentages of time spent in $t S-R$ sleep

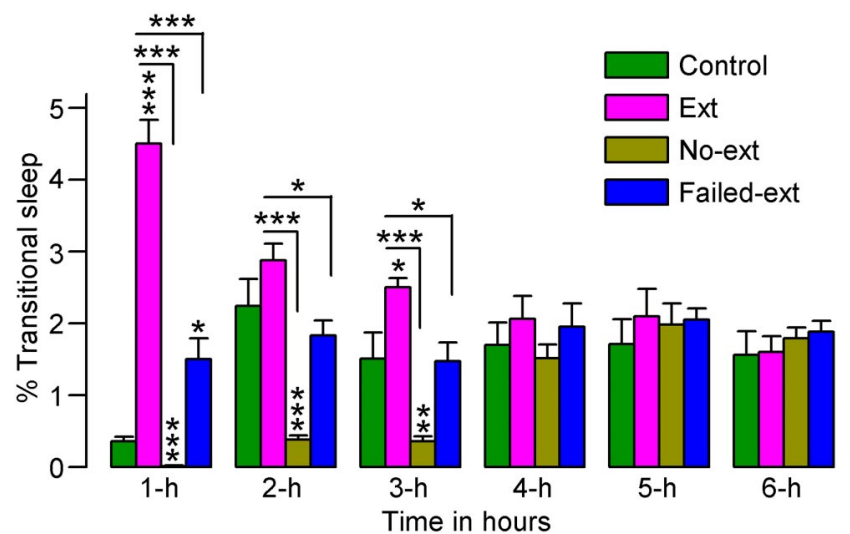

Figure 4. Effects of 45 min versus 15 min fear extinction training on the percentage of time spent in transitional sleep. These effects were observed during the $6 \mathrm{~h}$ sleep - wake recording period that immediately followed fear extinction training. Note the significant increase in transitional sleep during the first hour of sleep - wake recording in rats that received $45 \mathrm{~min}$ of training (Ext, $n=8$; Failed-ext, $n=6$ ) and the significant decrease in transitional sleep during the first $3 \mathrm{~h}$ of sleep - wake recording in rats that received only $15 \mathrm{~min}$ of training (No-ext, $n=$ 8). Also note the significant increase in transitional sleep during the first $3 \mathrm{~h}$ of sleep-wake recording in Ext rats compared with both No-ext and Failed-ext rats. Error bars represent SEM; ${ }^{*} p<0.05,{ }^{* *} p<0.01,{ }^{* * *} p<0.001$.

indicated significant main effects of group $\left(F_{(3,130)}=40, p<\right.$ $0.001)$ and group $\times$ time interaction $\left(F_{(15,130)}=11, p<0.001\right)$. During the first hour, compared with Control animals, both Ext $\left(t_{(15)}=12, p<0.001\right.$; Bonferroni post-tests $)$ and Failed-ext $\left(t_{(13)}=3.0, p<0.05\right)$ animals spent significantly more time in tS-R sleep (Fig. 4), indicating that the animals that had just concluded successful acquisition of fear extinction memory spent more time in $\mathrm{tS}-\mathrm{R}$ sleep. On the contrary, during the second and third hour, No-ext animals spent significantly less time in $\mathrm{tS}-\mathrm{R}$ sleep compared with Control animals $\left(t_{(15)}\right.$ values $>3.2, p<$ 0.01 ; Fig. 4), indicating that the reminder of context-associated fear without acquisition of context-associated fear extinction decreased $t S-R$ sleep. These results are consistent with the recent finding that antidepressant-induced suppression of tS-R sleep impairs hippocampus-dependent learning (Watts et al., 2012).

A two-factor ANOVA on the total percentages of time spent in REM sleep revealed significant main effects of group $\left(F_{(3,130)}=\right.$ $170, p<0.001)$, time $\left(F_{(3,130)}=64, p<0.001\right)$, and group $\times$ time interaction $\left(F_{(15,130)}=31, p<0.001\right)$. Post hoc comparisons revealed that, compared with Control animals, Ext animals during the first $4 \mathrm{~h}\left(t_{(15)}\right.$ values $\left.>3.6, p<0.01\right)$ and Failed-ext animals during the first $3 \mathrm{~h}\left(t_{(13)}\right.$ values $\left.>3.0, p<0.05\right)$ spent significantly more time in REM sleep (Fig. 5). These results suggest that the animals that had just concluded successful acquisition of fear extinction memory spent more time in REM sleep. On the contrary, during the second and third hours, No-ext animals spent significantly less time in REM sleep compared with Control animals $\left(t_{(15)}\right.$ values $>3.2, p<0.01$; Fig. 5), indicating that the reminder of context-associated fear without acquisition of context-associated fear extinction decreased REM sleep. Collectively, these data demonstrate that the acquisition of contextassociated fear extinction memory increases P-wave-associated sleep stages. These results are in agreement with other studies that have shown that REM sleep deprivation (via the flowerpot method) impaired recall of fear extinction memory in rats (Silvestri, 2005; Fu et al., 2007; Silvestri and Root, 2008). However, this particular method of REM sleep deprivation also eliminates a significant portion of NREM sleep and imposes high levels of stress on the animals. Additionally, none of these studies re- 
corded any physiological or behavioral signs of sleep. Thus, these limitations would make it difficult to conclude definitively that impaired fear extinction memory is caused primarily by a lack of REM sleep. Encouragingly, more recent studies in humans have also indicated that REM sleep could be involved in the development of fear extinction memory (Spoormaker et al., 2010, 2012).

\section{Potentiation of phasic $\mathrm{P}$-wave activity following contextual} fear extinction training depends on the duration of training and the individual animal

Although the P-wave is present during both tS-R and REM sleep, $\mathrm{tS}-\mathrm{R}$ sleep episodes are very short in duration and account for only $\sim 5 \%$ of the total number of P-waves. The other $95 \%$ of $\mathrm{P}$-waves appear during REM sleep episodes (Datta, 2000). Therefore, to determine the effects of fear extinction training on P-wave activity, we quantified $\mathrm{P}$-waves only during REM sleep episodes. These $\mathrm{P}$-wave counts were then expressed as REM sleep P-wave density (waves/ min of REM sleep) during each consecutive hour of the $6 \mathrm{~h} \mathrm{~S}-\mathrm{W}$ recording. Examples of REM sleep P-wave activity in Control and Ext animals are presented in Figure 6. A two-factor ANOVA on the $\mathrm{P}$-wave density data revealed significant main effects of group $\left(F_{(3,130)}=110, p<0.001\right)$, time $\left(F_{(3,130)}=\right.$ $88, p<0.001)$, and group $\times$ time interaction $\left(F_{(15,130)}=130, p<0.001\right)$. A post hoc comparison (Bonferroni post-test) revealed that $\mathrm{P}$-wave densities during the first $3 \mathrm{~h}$ were significantly higher in Ext animals compared with Control animals $\left(t_{(15)}\right.$ values $>12, p<0.001$; Fig. 7$)$, indicating that the acquisition of fear extinction memory increased $\mathrm{P}$-wave activity. To our surprise, a similar comparison with Failed-ext animals revealed that $\mathrm{P}$-wave densities were decreased in each of the $6 \mathrm{~h}$ of recording $\left(t_{(13)}\right.$ values $>2.9, p<0.05$; Fig. 7 ), indicating that $\mathrm{P}$-wave densities in these animals not only did not increase but in fact decreased after successful acquisition of fear extinction behavior. These data suggest that the increase or decrease in P-wave activity may not depend solely on the successful acquisition of fear extinction memory but also on the individual animal. The $\mathrm{P}$-wave densities in No-ext animals were not significantly different from those in Control and Failed-ext animals (Fig. 7), indicating that the reminder of fear without acquisition of fear extinction behavior did not cause any change in the P-wave density. However, the P-wave density in Noext animals was significantly less during the first $4 \mathrm{~h}$ compared with Ext animals $\left(t_{(15)}\right.$ values $>3.0, p<0.05$; Fig. 7). This finding further supports the hypothesis that the increased P-wave activity in Ext animals was caused, in part, by the acquisition of fear extinction behavior. Collectively, these data demonstrate that the potentiation of phasic $\mathrm{P}$-wave activity following fear extinction training depends on both the duration of training and the individual animal.

\section{Consolidation of context-associated fear extinction memory depends on the potentiation of REM sleep P-wave activity immediately after fear extinction training}

As documented above, after fear extinction training REM sleep $\mathrm{P}$-wave density increased for a period of $3 \mathrm{~h}$ in Ext animals, but not in Failed-ext or No-ext animals; and then, during fear extincanimals. Time scale, $5 \mathrm{~s}$.

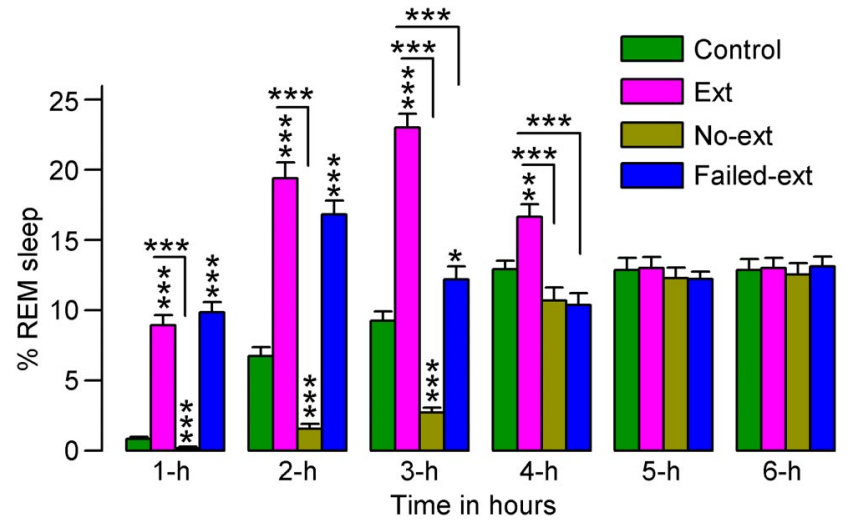

Figure 5. Effects of 45 min versus $15 \mathrm{~min}$ fear extinction training on the percentage of time spent in REM sleep. These effects were observed during the $6 \mathrm{~h}$ sleep — wake recording period that immediately followed fear extinction training. Note the significant increase in REM sleep during the first $4 \mathrm{~h}$ (Ext, $n=8$ ) and $3 \mathrm{~h}$ (Failed-ext, $n=6$ ) of sleep—wake recording in rats that received 45 min of training and the significant decrease in REM sleep during the first $3 \mathrm{~h}$ of sleep -wake recording in rats that received only $15 \mathrm{~min}$ of training ( $\mathrm{N}_{0}$-ext, $n=8$ ). Also note the significant increase and temporal differences in REM sleep in Ext rats compared with both No-ext and Failed-ext rats. Error bars represent SEM; ${ }^{*} p<0.05,{ }^{* *} p<0.01,{ }^{* * *} p<0.001$.
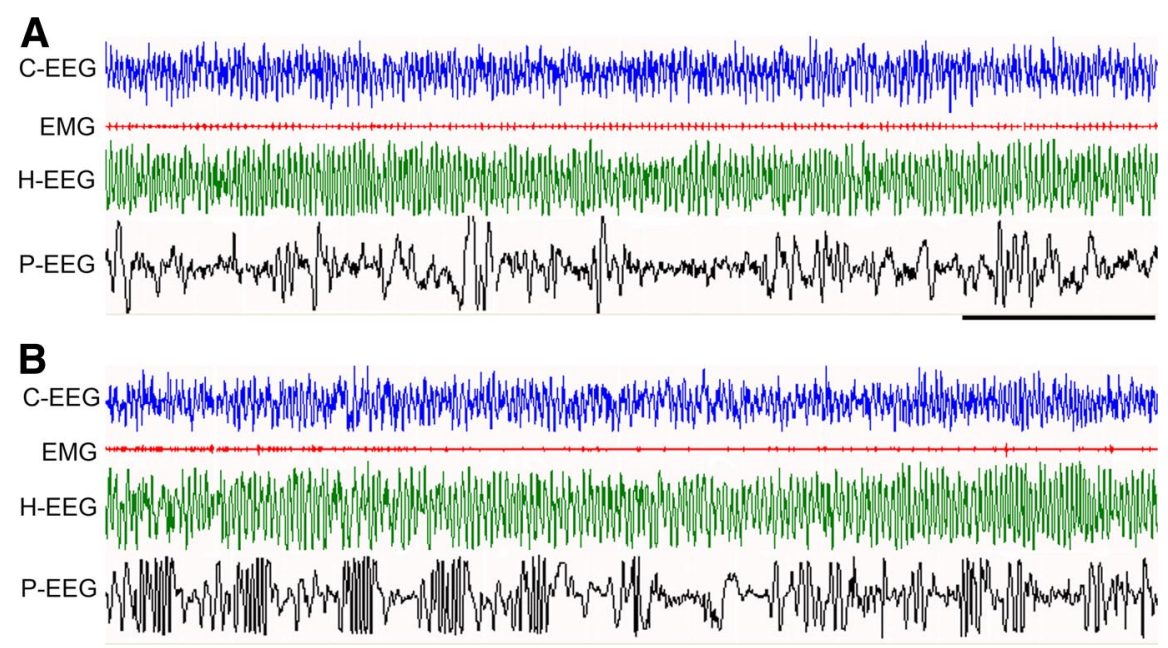

Figure 6. Sample polygraphic appearance of REM sleep in a Failed-ext $(\boldsymbol{A})$ and Ext $(\boldsymbol{B})$ rat at $\sim 1.5 \mathrm{~h}$ into the $6 \mathrm{~h}$ sleep-wake recording period that immediately followed the $45 \mathrm{~min}$ fear extinction training session. Note the qualitative similarity in both records showing characteristic electrographic signs of REM sleep: low-voltage, high-frequency waves recorded from the frontal the pontine EEG (P-EEG). Note that despite qualitative similarity, P-waves are more frequent in Ext animals than in Failed-ext

tion memory testing on the next day, only Ext animals exhibited behavioral signs of fear extinction memory. Thus, we suspected that there may be a causal relationship between individual animals' mean $\mathrm{P}$-wave density during this $3 \mathrm{~h}$ post-training period and the level of fear extinction memory expression during memory testing. Indeed, Spearman's rank correlation analysis revealed a strong inverse relationship between individual animals' $\mathrm{P}$-wave density after fear extinction training and their freezing responses during fear extinction memory testing (Spearman $r=$ $-0.954 ; p<0.001$; Fig. 8). These data demonstrates that the level of fear extinction memory retention is directly proportional to the level of phasic P-wave activity potentiation after fear extinction training. Since the retention of memory is dependent on successful acquisition and consolidation processes, and in this study the level of acquisition was equivalent in Ext and Failed-ext 


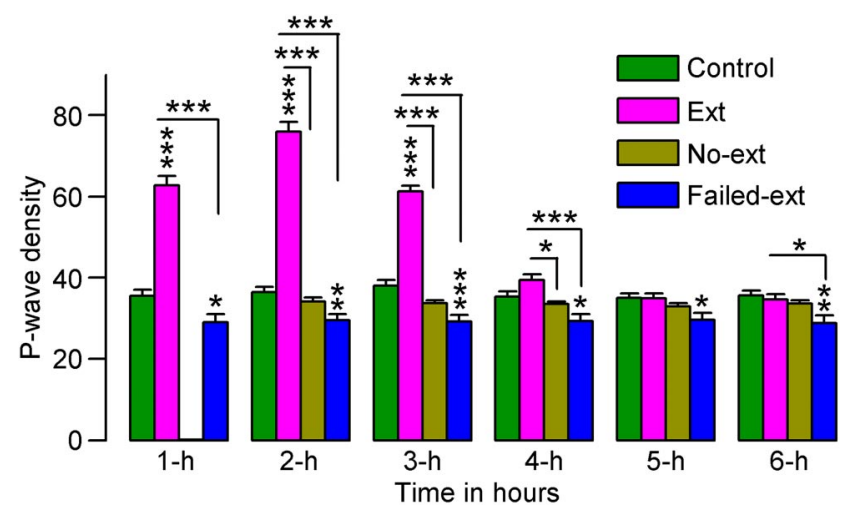

Figure 7. Effects of 45 min versus 15 min fear extinction training on P-wave density during REM sleep. These effects were observed during the $6 \mathrm{~h}$ sleep - wake recording period that immediately followed fear extinction training. Note that $45 \mathrm{~min}$ of training significantly increased P-wave density in some rats (Ext, $n=8$ ) but significantly decreased P-wave density in other rats (Failed-ext, $n=6$ ). Also note the significantly higher level of P-wave density in Ext rats compared with No-ext rats $(n=8)$. Error bars represent SEM; ${ }^{*} p<0.05,{ }^{* *} p<0.01$, ${ }^{* * *} p<0.001$.

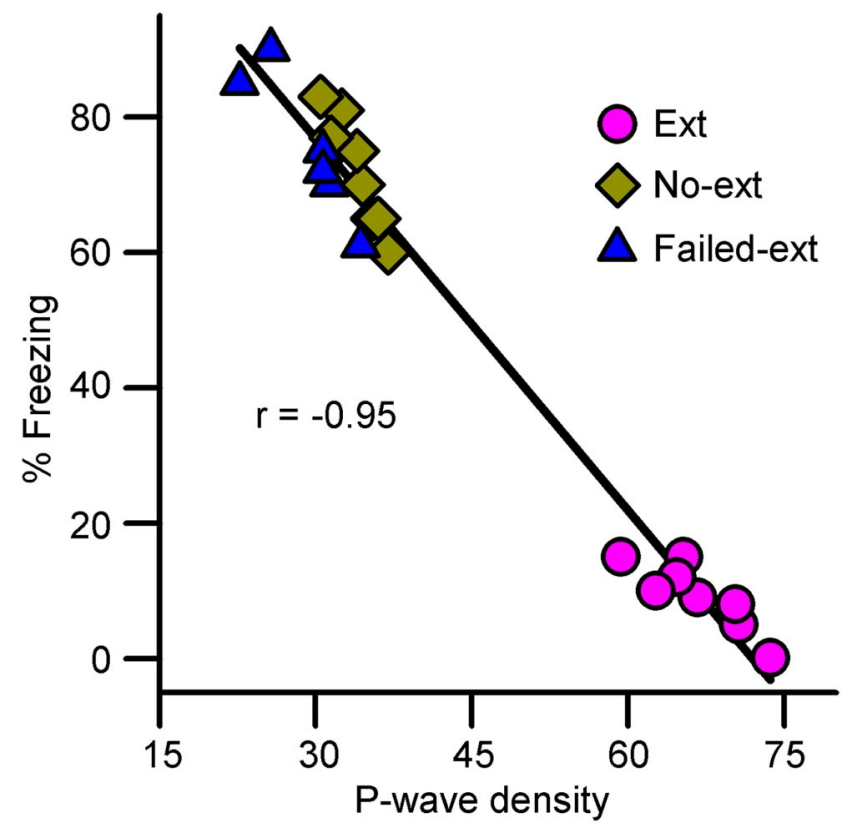

Figure 8. Relationship between freezing behavior during fear extinction memory testing and REM sleep P-wave density during the postextinction training $6 \mathrm{~h}$ sleep - wake period. Note the inverse relationship (Spearman rank correlation) between postextinction training REM sleep P-wave density and freezing response during fear extinction memory testing, $24 \mathrm{~h}$ after training.

animals, these data suggest that Failed-ext animals failed to consolidate fear extinction memory. These findings could be interpreted as evidence that the level of fear extinction memory consolidation is directly proportional to the amount of $\mathrm{P}$-wave activity potentiation after fear extinction training.

The $\mathrm{P}$-wave in the rat is the equivalent of the pontine component of the phasic ponto-geniculo-occipital (PGO) wave in the cat and nonhuman primates (Bizzi and Brooks, 1963; Datta, 2006). The $\mathrm{PGO} / \mathrm{P}$-wave is also present in humans, occurring immediately before and during REM sleep (Lim et al., 2007; Miyauchi et al., 2009). The P-wave occurs during REM sleep as a singlet and in clusters containing a variable number of waves (3-5 waves/burst) at a frequency range of 30-60 spikes/min (Datta et al., 1998; Datta, 2000). This wave is generated by the phasic activation of a group of glutamatergic cells in the dorsal part of the subceruleus nucleus in the pons (Datta and Hobson, 1994, 1995; Datta et al., 1998; Datta, 2006). These P-wave generating neurons discharge high-frequency (>500 Hz) spike bursts (3-5 spikes/ burst) on the background of tonically increased firing rates $(30-40 \mathrm{~Hz})$. Considering these facts about the mechanisms of $\mathrm{P}$-wave activity generation, the present finding that the potentiation of REM sleep P-wave activity after fear extinction training is the primary physiological stimulus for the retention of fear extinction memory is both very exciting and promising. It is exciting because a well characterized group of glutamatergic brainstem cells has never been shown to be involved in the consolidation of fear extinction memory.

\section{Discussion}

The collective findings discussed above provide clear experimental evidence to suggest that during the memory consolidation period after the acquisition of fear extinction learning, potentiation of REM sleep-associated phasic $\mathrm{P}$-wave activity in the brainstem is critical for the retention of fear extinction memory. The development and maturation of memory is a complex process occurring in several distinct stages over time. The two major stages of long-term memory formation are acquisition of information and consolidation of a memory trace (Datta, 2010). The first stage, acquisition, is when memories are initially formed or encoded by engaging with an object or performing an action, leading to the formation of a representation of the object or action within the brain. Following acquisition, the consolidation stage begins. Consolidation is a process whereby a memory trace, through the passage of time, becomes increasingly resistant to interference from competing or disrupting factors in the absence of further practice (McGaugh, 2000; Datta, 2010). Recent physiological and molecular accounts of memory suggest that a specific time period of undisturbed sleep and protein synthesis is necessary for the completion of both consolidation and reconsolidation processes (Karni et al., 1994; Abel et al., 1997; Nader et al., 2000; Walker et al., 2003; Datta et al., 2008; Datta, 2010). Based on this literature, it was expected that following retrieval of fear memory, animals would spend more time in sleep and less time in $\mathrm{W}$ for the reconsolidation of the labile fear memory trace. Contrary to this expectation, the present findings demonstrated that after a 15 min period of fear extinction training (No-ext animals), which allowed for retrieval of fear memory without acquisition of fear extinction memory, animals spent more time in $\mathrm{W}$ and less time in sleep. Although animals spent less time in all stages of sleep (SWS, tS-R, and REM sleep) during this expected fear memory reconsolidation period (Nader et al., 2000; Lattal and Abel, 2004), these reductions in sleep did not affect their fear memory when tested the next day (Fig. 1). These findings could be interpreted as evidence that fear memory reconsolidation can be completed without normal sleep. An alternative explanation could be that, unlike other types of memory, fear memory does not require reconsolidation.

Findings of this study also demonstrate that after $45 \mathrm{~min}$ of fear extinction training, the amount of time spent in all three stages of sleep increased in all animals. These findings are consistent with many other sleep and memory studies that have shown that, depending on the particular learning paradigm, specific sleep stages increase after learning (Smith, 1985; Datta, 2010; Diekelmann and Born, 2010; Poe et al., 2010). However, to our surprise, during testing on the next day, only $57.14 \%$ (Ext group) of the animals that exhibited increased sleep after fear extinction 
training retained an observable memory of this training. The other $42.86 \%$ (Failed-ext group) of animals failed to exhibit evidence of fear extinction memory. These findings are not in agreement with the interpretations of sleep and memory studies that have suggested that if training increases sleep then the increased sleep will certainly improve memory performance by enhancing the consolidation process. Therefore, the results of this study reveal that increased sleep after fear extinction training does not guarantee consolidation of a fear extinction memory trace.

Additionally, these findings suggest that exposure therapy to extinguish a fear response will reduce and/or eliminate anxietyprovoked sleep disturbances. This is an important finding because anxiogenic stress is one of the major causes of sleep disturbances, and continued sleep disturbances contribute to the development of a number of anxiety disorders, creating an undesirable positive feedback loop. The results of this study show that fear extinction training increased sleep in both Ext and Failed-ext groups, but fear extinction memory was consolidated only in the Ext group; this finding could be interpreted as support for the hypothesis that in addition to increased sleep, there could be an additional sleep-dependent factor(s) that was present in the Ext but not in the Failed-ext group of animals. Indeed, P-wave activity analysis of this study revealed that after fear extinction training, REM sleep P-wave density increased only in the Ext group of animals but not in the Failed-ext group of animals. Additionally, linear regression analysis of these data revealed a strong relationship between postextinction training REM sleep P-wave density and fear extinction memory expression. Therefore, these findings demonstrate that increased REM sleep P-wave activity was the critical sleep-associated factor that enabled consolidation of fear extinction memory in the Ext group of animals. This novel finding suggests that a specific area in the brainstem could be an important part of the distributed neuronal network for the regulation of emotional learning and memory.

The present finding that the potentiation of REM sleep $\mathrm{P}$-wave activity after fear extinction training is the primary physiological stimulus for the retention of fear extinction memory is both very exciting and promising. It is exciting because, as mentioned earlier, it is the first time that a well characterized group of glutamatergic brainstem cells has been shown to be involved in the consolidation of fear extinction memory. To the best of our knowledge, previous studies have not investigated the role of the brainstem in the development of fear extinction memory and/or regulation of fear memory, but instead have focused mainly on the forebrain areas, especially the hippocampus, amygdala, and prefrontal cortex (Graham and Milad, 2011; Milad and Quirk, 2012). This finding is promising because it will enable the design of future studies to understand the cellular and molecular interactions between the brainstem $\mathrm{P}$-wave generator and forebrain areas that are known to be involved in the regulation of fear extinction memory.

At this time, based on the existing literature, we can only speculate about the mechanisms underlying $\mathrm{P}$-wave generator activation-dependent fear extinction memory consolidation. For example, various cellular and molecular studies have demonstrated that glutamate-induced neuronal activation-dependent gene expression and protein synthesis in the dorsal hippocampus and amygdala are necessary for memory processing and behavioral plasticity (Guzowski et al., 2001; Kandel, 2001; Ribeiro et al., 2002; Lee et al., 2004). Also, BDNF has been shown to contribute to neuronal activity-dependent processes such as long-term potentiation (Bramham and Messaoudi, 2005) and associative memory formation (Bliss and Collingridge, 1993; Whitlock et al.,
2006). There is increasing behavioral evidence indicating that BDNF gene expression is induced in the hippocampus after contextual and spatial learning and that this mechanism is essential for normal learning and memory (Hall et al., 2000). More importantly, consolidation of fear extinction memory requires plasticity within the prefrontal cortex, hippocampus, and amygdala, which in turn depends on NMDA receptors, protein kinases, and protein synthesis (Milad and Quirk, 2002; Peters et al., 2010). Additionally, it has been shown that the dorsal hippocampus and amygdala receive direct anatomical projections from $\mathrm{P}$-wavegenerating cells and activation of the $\mathrm{P}$-wave generator increases both glutamate release in the dorsal hippocampus and frequency of hippocampal theta wave activity (Datta et al., 1998; Karashima et al., 2004; Datta, 2006). More recently, studies have shown that the activation of the $\mathrm{P}$-wave generator increases expression of pCREB, Arc, and BDNF proteins and Egr-1, Arc, and BDNF mRNA expressions in the dorsal hippocampus and amygdala (Datta et al., 2008). The synthesis of this information engenders the hypothesis that the activation of $\mathrm{P}$-wave-generating cells in the brainstem is a neurochemical switch that increases glutamate release in the forebrain areas, especially in the dorsal hippocampus and amygdala, to activate NMDA receptors. Such activation could then ultimately initiate or intensify the cellular and molecular steps in the forebrain that are necessary for the consolidation of fear extinction memory. This possibility is clinically significant because aberrant BDNF expression continues to be implicated in psychiatric disorders associated with cognitive dysfunction (e.g., schizophrenia, PTSD, depression, and bipolar disorder) (Soliman et al., 2010); thus, increasing phasic activation processes in REM sleep may be a viable noninvasive therapeutic technique to restore cognitive function in these disorders.

In summary, these experiments identified extinction traininginduced potentiation of brainstem $\mathrm{P}$-wave generator activity as a critical factor in the development of fear extinction memory. The discovery of this unique mechanism will not only significantly improve our present understanding of the cellular and molecular mechanisms that underlie the regulation of emotional memory, but could also facilitate the development of a new treatment method for clinical disorders of fear and anxiety in humans that is more focused and efficacious than existing methods that incorporate only fear extinction.

\section{References}

Abel T, Nguyen PV, Barad M, Deuel TA, Kandel ER, Bourtchouladze R (1997) Genetic demonstration of a role for PKA in the late phase of LTP and in hippocampus-based long-term memory. Cell 88:615-626. CrossRef Medline

Anderson KC, Insel TR (2006) The promise of extinction research for the prevention and treatment of anxiety disorders. Biol Psychiatry 60:319-321. CrossRef Medline

Bizzi E, Brooks DC (1963) Functional connections between pontine reticular formation and lateral geniculate nucleus during deep sleep. Arch Ital Biol 101:666-680. Medline

Blanchard RJ, Blanchard DC (1969) Passive and active reactions to feareliciting stimuli. J Comp Physiol Psychol 68:129-135. CrossRef Medline

Bliss TV, Collingridge GL (1993) A synaptic model of memory: long-term potentiation in the hippocampus. Nature 361:31-39. CrossRef Medline

Bouton ME, Westbrook RF, Corcoran KA, Maren S (2006) Contextual and temporal modulation of extinction: behavioral and biological mechanisms. Biol Psychiatry 60:352-360. CrossRef Medline

Bramham CR, Messaoudi E (2005) BDNF function in adult synaptic plasticity: the synaptic consolidation hypothesis. Prog Neurobiol 76:99-125. CrossRef Medline

Choi DC, Maguschak KA, Ye K, Jang SW, Myers KM, Ressler KJ (2010) Prelimbic cortical BDNF is required for memory of learned fear but not 
extinction or innate fear. Proc Natl Acad Sci U S A 107:2675-2680. CrossRef Medline

Cukor J, Olden M, Lee F, Difede J (2010) Evidence-based treatments for PTSD, new directions, and special challenges. Ann NY Acad Sci 1208:8289. CrossRef Medline

Datta S (2000) Avoidance task training potentiates phasic pontine-wave density in the rat: A mechanism for sleep-dependent plasticity. J Neurosci 20:8607-8613. Medline

Datta S (2006) Activation of phasic pontine-wave generator: a mechanism for sleep-dependent memory processing. Sleep Biol Rhythms 4:16-26. CrossRef

Datta S (2010) Sleep: learning and memory. In: Encyclopedia of behavioral neuroscience, Vol 3, pp 218-226. New York: Elsevier.

Datta S, Hobson JA (1994) Neuronal activity in the caudo-lateral peribrachial pons: Relationship to PGO waves and rapid eye movements. J Neurophysiol 71:95-109. Medline

Datta S, Hobson JA (1995) Suppression of ponto-geniculo-occipital waves by neurotoxic lesions of pontine caudo-lateral peribrachial cells. Neurosci 67:703-712. CrossRef

Datta S, Siwek DF, Patterson EH, Cipolloni PB (1998) Localization of pontine PGO wave generation sites and their anatomical projections in the rat. Synapse 30:409-423. CrossRef Medline

Datta S, Mavanji V, Ulloor J, Patterson EH (2004) Activation of phasic pontine-wave generator prevents rapid eye movement sleep deprivationinduced learning impairment in the rat: a mechanism for sleepdependent plasticity. J Neurosci 24:1416-1427. CrossRef Medline

Datta S, Li G, Auerbach S (2008) Activation of phasic pontine-wave generator in the rat: a mechanism for expression of plasticity-related genes and proteins in the dorsal hippocampus and amygdala. Eur J Neurosci 27: 1876-1892. CrossRef Medline

Diekelmann S, Born J (2010) The memory function of sleep. Nat Rev Neurosci 11:114-126. Medline

Doyère V, Gisquet-Verrier P, de Marsanich B, Ammassari-Teule M (2000) Age-related modifications of contextual information processing in rats: role of emotional reactivity, arousal and testing procedure. Behav Brain Res 114:153-165. CrossRef Medline

Fu J, Li P, Ouyang X, Gu C, Song Z, Gao J, Han L, Feng S, Tian S, Hu B (2007) Rapid eye movement sleep deprivation selectively impairs recall of fear extinction in hippocampus-independent tasks in rats. Neuroscience 144: 1186-1192. CrossRef Medline

Graham BM, Milad MR (2011) The study of fear extinction: implications for anxiety disorders. Am J Psychiatry 168:1255-1265. CrossRef Medline

Guzowski JF, Setlow B, Wagner EK, McGaugh JL (2001) Experiencedependent gene expression in the rat hippocampus after spatial learning: a comparison of the immediate-early genes Arc, c-fos, and zif268. J Neurosci 21:5089-5098. Medline

Hall J, Thomas KL, Everitt BJ (2000) Rapid and selective induction of BDNF expression in the hippocampus during contextual learning. Nat Neurosci 3:533-535. CrossRef Medline

Kandel ER (2001) The molecular biology of memory storage: a dialogue between genes and synapses. Science 294:1030-1038. CrossRef Medline

Karashima A, Nakao M, Honda K, Iwasaki N, Katayama N, Yamamoto M (2004) Theta wave amplitude and frequency are differentially correlated with pontine waves and rapid eye movements during REM sleep in rats. Neurosci Res 50:283-289. CrossRef Medline

Karni A, Tanne D, Rubenstein BS, Askenasy JJ, Sagi D (1994) Dependence on REM sleep of overnight improvement of a perceptual skill. Science 265:679-682. CrossRef Medline

Lattal KM, Abel T (2004) Behavioral impairments caused by injections of the protein synthesis inhibitor anisomycin after contextual retrieval reverse with time. Proc Natl Acad Sci U S A 101:4667-4672. CrossRef Medline

Lavie P (2001) Sleep disturbances in the wake of traumatic events. N Engl J Med 345:1825-1832. CrossRef Medline

Lee JL, Everitt BJ, Thomas KL (2004) Independent cellular processes for hippocampal memory consolidation and reconsolidation. Science 304:839-843. CrossRef Medline

Lim AS, Lozano AM, Moro E, Hamani C, Hutchison WD, Dostrovsky JO, Lang AE, Wennberg RA, Murray BJ (2007) Characterization of REMsleep associated ponto-geniculo-occipital waves in the human pons. Sleep 30:823-827. Medline
Maren S (2007) Neuroscience. The threatened brain. Science 317:1043-1044. CrossRef Medline

McGaugh JL (2000) Memory-a century of consolidation. Science 287: 248-251. CrossRef Medline

Mellman TA, Pigeon WR, Nowell PD, Nolan B (2007) Relationships between REM sleep findings and PTSD symptoms during the early aftermath of trauma. J Trauma Stress 20:893-901. CrossRef Medline

Milad MR, Quirk GJ (2002) Neurons in medial prefrontal cortex signal memory for fear extinction. Nature 420:70-74. CrossRef Medline

Milad MR, Quirk GJ (2012) Fear extinction as a model for translational neuroscience: ten years of progress. Annu Rev Psychol 63:129-151. CrossRef Medline

Miyauchi S, Misaki M, Kan S, Fukunaga T, Koike T (2009) Human brain activity time-locked to rapid eye movements during REM sleep. Exp Brain Res 192:657-667. CrossRef Medline

Nader K, Schafe GE, Le Doux JE (2000) Fear memories require protein synthesis in the amygdala for reconsolidation after retrieval. Nature 406: 722-726. CrossRef Medline

Pace-Schott EF, Verga PW, Bennett TS, Spencer RM (2012) Sleep promotes consolidation and generalization of extinction learning in simulated exposure therapy for spider fear. J Psychiat Res 46:1036-1044. CrossRef Medline

Paxinos G, Watson C (1997) The rat brain in stereotaxic coordinates. San Diego: Academic.

Peters J, Dieppa-Perea LM, Melendez LM, Quirk GJ (2010) Induction of fear extinction with hippocampal-infralimbic BDNF. Science 328:1288-1290. CrossRef Medline

Poe GR, Walsh CM, Bjorness TE (2010) Cognitive neuroscience of sleep. Prog Brain Res 185:1-19. CrossRef Medline

Ribeiro S, Mello CV, Velho T, Gardner TJ, Jarvis ED, Pavlides C (2002) Induction of hippocampal long-term potentiation during waking leads to increased extrahippocampal zif-268 expression during ensuing rapideye-movement sleep. J Neurosci 22:10914-10923. Medline

Rothbaum BO, Davis M (2003) Applying learning principles to the treatment of post-trauma reactions. Ann NY Acad Sci 1008:112-121. CrossRef Medline

Silvestri AJ (2005) REM sleep deprivation affects extinction of cued but not contextual fear conditioning. Physiol Behav 84:343-349. CrossRef Medline

Silvestri AJ, Root DH (2008) Effects of REM deprivation and an NMDA agonist on the extinction of conditioned fear. Physiol Behav 93:274-281. CrossRef Medline

Smith C (1985) Sleep states and learning: a review of the animal literature. Neurosci Biobehav Rev 9:157-168. CrossRef Medline

Soliman F, Glatt CE, Bath KG, Levita L, Jones RM, Pattwell SS, Jing D, Tottenham N, Amso D, Somerville LH, Voss HU, Glover G, Ballon DJ, Liston C, Teslovich T, Van Kempen T, Lee FS, Casey BJ (2010) A genetic variant BDNF polymorphism alters extinction learning in both mouse and human. Science 327:863-866. CrossRef Medline

Spoormaker VI, Sturm A, Andrade KC, Schröter MS, Goya-Maldonado R, Holsboer F, Wetter TC, Sämann PG, Czisch M (2010) The neural correlates and temporal sequence of the relationship between shock exposure, disturbed sleep and impaired consolidation of fear extinction. J Psychiatr Res 44:1121-1128. CrossRef Medline

Spoormaker VI, Schröter MS, Andrade KC, Dresler M, Kiem SA, GoyaMaldonado R, Wetter TC, Holsboer F, Sämann PG, Czisch M (2012) Effects of rapid eye movement sleep deprivation on fear extinction recall and prediction error signaling. Hum Brain Mapp 33:2362-2376. CrossRef Medline

Walker MP, Brakefield T, Hobson JA, Stickgold R (2003) Dissociable stages of human memory consolidation and reconsolidation. Nature 425:616-620. CrossRef Medline

Watts A, Gritton HJ, Sweigart J, Poe GR (2012) Antidepressant suppression of nonREM sleep spindles and REM sleep impairs hippocampusdependent learning while augmenting striatum-dependent learning. J Neurosci 32:13411-13420. CrossRef Medline

Wellman LL, Yang L, Tang X, Sanford LD (2008) Contextual fear extinction ameliorates sleep disturbances found following fear conditioning in rats. Sleep 31:1035-1042. Medline

Whitlock JR, Heynen AJ, Shuler MG, Bear MF (2006) Learning induces long-term potentiation in the hippocampus. Science 313:1093-1097. CrossRef Medline 